\title{
DOÑA MORALES: TENSÃO E PÓS-COLONIALIDADE NA OBRA DE ERASMO LINHARES
}

\author{
Alexandre da Silva Pimentel ${ }^{1}$
}

\begin{abstract}
RESUMO: Em 1492, os conquistadores estrangeiros apareciam pela primeira vez no horizonte e davam início ao que viria a ser um dos pontos mais significativos na história deste continente: o "descobrimento". Este choque de culturas e temporalidades distintas será tomado como ponto referencial para o desenvolvimento de algumas reflexões sobre a relevância do discurso como instrumento de poder e dominação utilizada pelo Império ao longo do processo colonial. Tal processo exigiu das culturas colonizadas posturas que lhes possibilitassem continuar vivas no interior de um contexto hegemônico e aculturador. Nestas circunstâncias o discurso pós-colonial, em tensão com a retórica etnocêntrica do Império, vai buscar construir possibilidades capazes de resistir na esfera discursiva e subverter os temas, os mitos de poder, raça e subordinação sustentados pelo discurso de expansão imperial. Este artigo buscou analisar a natureza desta resposta pós-colonial e o modo como se configuram as representações de seus conflitos no texto de um autor oriundo de uma região historicamente marcada pela colonização, a saber, a Amazônia. A análise foca-se no conto Doña Morales, presente no livro $O$ tocador de charamela (1979) do escritor amazonense Erasmo Linhares (1934-1999), e busca perceber como o discurso pós-colonial se articula no texto literário para estabelecer questionamentos às construções discursivas coloniais e, sob a égide destes questionamentos, responder a elas.
\end{abstract}

PALAVRAS-CHAVE: Pós-colonialidade; Discurso; América Latina; Colonização; Erasmo Linhares.

ABSTRACT: In 1492, the foreign conquerors for the first time appeared on the horizon and began what would become one of the most significant points in the history of this continent: the "discovery." This clash of distinct cultures and temporalities will be taken as a reference point for the development of some reflections about the relevance of discourse as an instrument of power and domination used by the Empire throughout the colonial process. Such a process demanded of colonized cultures postures that would enable them to remain alive within a hegemonic and acculturating context. In these circumstances the postcolonial discourse, in tension with the empiricist ethnocentric rhetoric, seeks to construct possibilities capable of resisting in the discursive sphere and subvert the themes, the myths of power, race and subordination sustained by the discourse of imperial expansion. This work sought to analyze the nature of this postcolonial response and the way in which the representations of their conflicts are configured in the text of an author coming from a region historically marked by colonization, namely the Amazon. The analysis focuses on the short story Doña Morales, present in the book $O$ tocador de charamela (1979) by the Amazonian writer Erasmo Linhares (1934-1999), and seeks to understand how the postcolonial discourse articulates itself in the literary text to question the colonial discursive constructions and, under the aegis of these questions, respond to them.

KEYWORDS: Postcoloniality; Discourse; Latin America; Colonization; Erasmo Linhares.

Afinal de contas, o que é a realidade, o que é a existência senão este choque de personalidades, claras umas, outras opacas, que se cruzam, que se encontram, que se opõem, que se unem, que se separam, que se violentam uns aos outros mas que constituem esta admirável harmonia de alegria e tristeza, de dor e de prazer, de comédia e de tragédia que é a própria vida? L. Ruas

\footnotetext{
${ }^{1}$ Mestre em Letras e Artes pela Universidade do Estado do Amazonas. Graduado em Letras Língua Portuguesa pela mesma universidade. Professor Assistente do Curso de Letras Mediado por Tecnologia da Universidade do Estado do Amazonas (UEA). E-mail: allexandrepimental@gmail.com
} 


\section{A PRODUÇÃO DISCURSIVA DO OUTRO}

1492 é um ano marcante na história das populações de todo o continente latinoamericano. Os conquistadores estrangeiros apareciam pela primeira vez no horizonte e davam início ao que viria a ser um dos pontos mais significativos na história deste continente: o "descobrimento". Este choque de culturas e temporalidades distintas, dada sua expressiva importância histórica para os povos de ambos os lados envolvidos, pode ser tomado como ponto referencial para começarmos a pensar o processo colonial para além de uma dominação política, geográfica e humana; para começarmos a pensá-lo para além de um enfrentamento físico entre forças opostas e desiguais. Ao deslocar um pouco o olhar, será possível perceber que, apesar da importância da força e das técnicas científicas utilizadas pelos colonos para subjugar os povos ameríndios, um outro fator assumiu vital importância para o sucesso da empresa colonial: o discurso.

Se por um lado, é através da superioridade científica e tecnológica - refletida nas técnicas de ocupação e guerrilha, modernas embarcações, técnicas de navegação, armas de fogo, etc. - e da violência que o processo colonial se impõe estruturalmente, por outro, é através do discurso que ele se solidifica. É na esfera discursiva que o processo de enfraquecimento da cultura nativa diante da imposição ideológica de superioridade cultural e racial europeia se dá com mais força. Segundo Santos, "o império foi, em grande parte, um exercício textual: relatórios de burocratas coloniais, anúncios, tratados políticos, diários, editais, cartas, romances de aventura, todos continham ideais imperiais de orgulho racial e poder nacional" (SANTOS, 2010, p. 343). Este discurso vai, através das suas múltiplas formas, implementar uma narrativa eivada de interesses políticos e econômicos que contará a história ao mundo sob uma perspectiva relativamente unilateral.

Tal narrativa, ou literatura colonialista, como a denomina Santos, é "aquela, especificamente, voltada para a expansão colonial, em geral literatura escrita por europeus e de um ponto de vista europeu sobre terras e povos não-europeus por eles dominados" (SANTOS, 2010, p. 343). Este discurso colonial atua como uma eficaz estratégia para subjugar ideologicamente o nativo, uma vez que política e geograficamente ele já o está. "O colonialismo não se satisfaz em prender o povo nas suas redes, em esvaziar o cérebro do colonizado de toda forma e de todo conteúdo. Por uma espécie de perversão da lógica, ele se orienta para o passado do povo oprimido e o distorce, desfigura, aniquila" (FANON, 2002, p. 244). 
Ora, uma vez destruído ou desfigurado o passado de um povo, este perde as referências que são primordiais para a construção de uma identidade vinculada a este legado cultural que era contrário aos interesses externos. Uma vez destruída a história e a cultura de um povo, as identidades das novas gerações serão construídas imersas em valores, mitos de poder e histórias que intentam, veladamente ou não, internalizar a superioridade racial e cultural europeia. Com sua história e cultura destruídas, ou ainda, desfiguradas, o colonizado passa a vê-las como algo feio e ruim, símbolo do atraso e da falta de discernimento que os aprisionava e os impedia de crescer antes da chegada da "luz civilizatória do império". Em contraposição ao "glorioso" manancial cultural europeu, o colonizado vai aos poucos renegando, diminuindo e ridicularizando sua própria história, cultura, língua, imaginário e, posteriormente, sua própria fisiologia.

A este respeito é interessante citar como exemplo o fato de que o índio romântico brasileiro pode ser considerado um passo importante na desconstrução desta narrativa colonialista na medida em que passa a ser inserido, em alguns romances, como herói soberbo, honrado e corajoso que interage com o branco colonizador ou com aquele que é associado a este simbolicamente. Porém, ao analisarmos os romances indianistas de um Alencar, por exemplo, é possível perceber que esta desconstrução se torna apenas parcial, se levarmos em consideração dois pontos: o primeiro deles nos aponta Bosi quando nos diz que

Tanto nos romances nativistas ( $O$ guarani, Iracema, Ubirajara) como aqueles em que o bom selvagem se desdobra em heróis regionais ( $O$ gaúcho, $O$ sertanejo), o selo da nobreza é dado pelas forças do sangue que o autor reconhece e respeita igualmente na estirpe dos colonizadores brancos. Ao heroísmo de Peri não deixa de apor a sobranceria de Dom Antônio de Mariz e sua esposa, os castelões impávidos de $O$ guarani. (BOSI, 2006, p. 138 grifos do autor).

O desnível das relações sociais e a inferiorização do nativo diante do colono europeu é pontuada nestes romances e leva o leitor a divisar uma espécie de supremacia racial e cultural que subjuga a força e a grandeza da cultura nativa, obrigando-a a se portar em posição de subalternidade e submissão ao poder e requinte cultural externo. Estas contradições, encontradas no cerne de um movimento que trazia como uma das principais características a busca e a valorização da identidade nacional (e tendo no índio brasileiro, talvez o maior símbolo desta identidade), podem suscitar questionamentos interessantes sobre a real profundidade e alcance dos ímpetos nativistas no romantismo brasileiro.

O segundo ponto trata da idealização medieval usada na construção destes personagens. Ora, para concretizar o ímpeto de criar uma literatura realmente nacional, era necessário primeiro encontrar ou construir uma identidade nacional; tal objetivo só poderia ser 
alcançado por um retorno ao passado, às suas raízes, às suas origens nativas. Mas ao fazer este retorno o que o intelectual brasileiro do século XIX encontrava? O índio, o mestiço, o negro escravo. Ao comparar a sua ancestralidade com a pureza étnica e a abrangente força cultural europeia, este intelectual sentia-se constrangido; tinha vergonha das suas origens e a solução encontrada por ele foi o idealismo. O índio que vemos nestas obras é um índio medievalizado; idealizado com características do herói romântico europeu, ou seja, ele era construído e moldado sob a perspectiva das virtudes e costumes europeus.

Estas contradições do ufanismo romântico do século XIX, se por um lado apontam para uma sensível dificuldade dos autores brasileiros da época em se desvencilharem totalmente de um discurso desenvolvido por uma perspectiva colonialista e inserido nas regiões colonizadas ao longo dos séculos, por outro já nos possibilita entrever uma tensão discursiva entre este ufanismo romântico que inicia um movimento de mergulho na sua própria história e cultura através do resgate, pesquisa e valorização da cultura nacional pré-colonização e os impulsos externos de um discurso colonialista.

Deste modo, passamos a perceber a colonização, enquanto exercício discursivo, de um modo mais nítido; e isto é fundamental para que possamos compreender a noção de produção discursiva do outro em um contexto hegemônico e, portanto, não-dialógico. Esta produção é potencialmente exótica; no sentido de que um olhar externo e recém-chegado a uma determinada realidade vai buscar descrevê-la, caracterizá-la, traduzi-la, torná-la visível e sensível a um leitor externo a esta mesma realidade, um leitor que se encontra do outro lado do oceano. ${ }^{2}$ Esta retórica exótica vai atingir muitos desdobramentos ao longo dos séculos e, extrapolando a mera descrição e informação, se lançará também ao campo científico e às artes para explicar, contar e representar o estranho recém-descoberto. Mas trata-se de uma retórica etnocêntrica e subjugadora, pois

[...] a alteridade que o exotismo implica tem um caráter muito relativo, porque não é mais do que um pretexto para desenvolvimentos baseados em problemáticas próprias do observador. Falando sobre o Outro, falando para o Outro, o discurso exótico só mediocremente pode exprimir a diferença. E, sobretudo, vai revelar-se, ao fim e ao cabo, incapaz de verdadeiramente dar a palavra ao outro e de o escutar [...] (MOURALIS, 1982, p. 112-113).

\footnotetext{
${ }^{2}$ Tendo a história brasileira como referência, cita-se, como exemplos, a carta de Pero Vaz de Caminha a D. Manoel no séc. $\mathrm{XV}$, dando notícias sobre a nova terra descoberta e referindo-lhe suas impressões sobre a natureza e os aborígenes que aqui viviam; e também $O$ tratado descritivo do Brasil de Gabriel Soares, datando de 1587, entre tantos textos de informação produzidos ao longo da empresa colonial.
} 
Tomar a palavra para si e construir possibilidades capazes de resistir na esfera discursiva e subverter os temas, os mitos de poder, raça e subordinação sustentados pelo discurso de expansão imperial será, a partir do momento em que o nativo se dá conta da força do discurso em todo este processo colonial, sua busca intelectual; esta, por sua vez, ligada diretamente à tentativa de reconstrução do passado sob outra ótica. "E foi na recriação épica do passado que os primeiros nacionalistas encontraram um meio de contra-escrever sua representação colonial e reinscrever-se nessa nova história." (SANTOS, 2010, p. 344).

Eduard W. Said em seu livro Orientalismo: O Oriente como invenção do Ocidente, nos mostra como a hegemonia vai se concretizando no decorrer da história e fabricando percepções que vão aos poucos se tornando convicções amplamente aceitas sem serem devida e criticamente questionadas; o modo como o Ocidente, em relação ao Oriente, vai fazendo "afirmações a seu respeito, descrevendo-o, ensinando-o, colonizando-o, governando-o", diz Said; o modo como a cultura europeia vai, através do discurso, produzindo o "Oriente política, sociológica, militar, ideológica, científica e imaginativamente durante o período do pósiluminismo" (SAID, 2007, p. 29). Deslocando o cenário das reflexões de Said para a realidade histórica e cultural do "novo continente", este artigo vai buscar analisar as representações destas tensões advindas do processo colonial na obra de Erasmo Linhares, mais especificamente no conto Doña Morales, e perceber como o discurso pós-colonial se configura e se articula no texto literário para estabelecer questionamentos às construções discursivas coloniais e, sob a égide destes questionamentos, responder a elas.

\section{A POSTURA PÓS-COLONIAL}

O termo pós-colonial tem gerado controversas e distintas interpretações. Para alguns estudiosos, este "pós" pode significar o surgimento ou o início de uma condição colonial ao demarcar, temporalmente, distintas realidades históricas, a saber: o "antes" e o "após" a chegada do Império.

Para outros, este "pós" pode significar exatamente o oposto, ou seja, o momento em que a colônia consegue se desvencilhar dos laços coloniais com a metrópole e obtém sua independência política. Neste sentido, o referido termo significa não a chegada, mas a partida do poder imperial.

Outros estudiosos questionam ainda a profundidade da noção de pós-colonial aplicada a ideia de fim da dominação e do processo colonial. Argumentam que a independência trazida pela revolução não significa, necessariamente, o fim da exploração e do domínio político e 
econômico. Para Mata, muitas vezes o colonialismo, ao invés de esmorecer, nestas circunstâncias, se solidifica

[...] através de situações que representam uma reedição dos objectivos (sic) e métodos do "antigo período", colonial, pelo "novo período", o do pósindependência, [desta maneira], é posto a descoberto o modo como este também participa na "larga história de crueldade em que o colonialismo é uma página a mais." (MATA, 2000, p. 2 grifos do autor).

Alguns personagens do escritor Angolano José Eduardo Agualusa em $O$ ano em que zumbi tomou o rio (2008), romance que narra a revolta armada das minorias étnicas historicamente exploradas e marginalizadas no Rio de Janeiro, parecem concordar com o pensamento de Mata. O personagem Euclides, por exemplo, em uma conversa com um traficante sobre tensão racial no Brasil, diz: "Sabe qual a diferença entre Angola e o Brasil? Ambos são países independentes, sim, mas ao contrário de Angola o Brasil nunca foi descolonizado. Um príncipe Português proclamou a independência do Brasil e desde então os brancos nunca mais abandonaram o poder. [...]" (AGUALUSA, 2008, p.83).

A frase do personagem Euclides sintetiza muito bem a tônica ideológica que costura toda a trama do romance. Através de um retorno constante aos passados coloniais: brasileiro e angolano (ambas nações colonizadas por Portugal e colocadas em constante posição de diálogo ao longo da narrativa), Agualusa não apenas questiona a profundidade ou o alcance desta descolonização brasileira, mas afirma, (a partir da constatação das desigualdades, injustiças e a desvalorização cultural, moral e humana das minorias - aspectos que são reflexos diretos de um regime colonial e que vem se perpetuando e assumindo novas formas e mecanismos ao longo da história brasileira) que a descolonização nunca aconteceu de fato no Brasil. Para o autor, “[...] Enquanto não enfrentar o problema e der maior participação aos negros, o Brasil não terá se descolonizado.” (AGUALUSA, 2004).

Como se pode perceber, a noção de pós-colonial, nas duas principais acepções mostradas, está ligada a uma espécie de demarcação temporal e histórica; e Mata já começa a questionar esta demarcação mostrando que o colonialismo precisa ser pensado para além desta. Pensar para além é justamente despojar um pouco o termo deste aspecto demarcatório para começar a desenhar uma interpretação mais profunda de seu significado.

Neste novo desenho interpretativo, assumem maior relevância o pensamento, a reflexão, o discurso e a resistência. O termo pós-colonial, portanto, deixa de ser compreendido como início ou fim de uma dominação imperial geopolítica, e passa a ser entendido como uma 
postura reflexiva e contra-discursiva diante das significações e instituições erguidas e difundidas pelo Império ao longo dos séculos.

Para Mata, “[...] o pós-colonial pressupõe uma nova visão da sociedade que reflecte (sic) sobre a sua própria condição periférica [...]" (MATA 2000, p. 1). Portanto, trata-se de um momento no qual um povo toma consciência de sua cultura, de sua história e de sua situação periférica em um contexto hegemônico e, a partir disso, passa a adotar uma postura reflexiva e questionadora sobre si mesmo e sobre o discurso do colonizador; um momento em que o povo começa a buscar ou a construir espaços nos quais possa expressar sua legitimidade sociocultural e questionar as significações, os mitos de poder, raça e subordinação que sustentam a expansão colonial ${ }^{3}$. Em suma, o pós-colonial é muito mais um estado de consciência, reflexão, questionamento e luta do que uma referência de balizamento histórico, temporal, político ou geográfico.

\section{UM OUTRO OLHAR}

É com esta perspectiva, e também com as demais reflexões desenvolvidas até agora, que nos propomos a fazer uma leitura do conto Doña Morales, do escritor amazonense Erasmo Linhares (1934-1999). Este conto faz parte do livro $O$ tocador de charamela, publicado originalmente em 1979. A obra traz, em sua composição, variadas temáticas citadinas, folclóricas e indígenas, além de um conjunto de três contos chamado "três estórias da terra", no qual a realidade vivida pelos trabalhadores nos seringais de extração da borracha lhe serve de matéria prima para a abordagem dos conflitos, sentimentos destes homens que viviam em condições precárias e isolados na floresta fomentando a riqueza dos áureos tempos da borracha no Amazonas.

O conto analisado neste trabalho narra uma estória que se passa em uma antiga vila do altiplano boliviano, "nascida à sombra da fortificação espanhola de San Salvador" (LINHARES, 2005, p. 55). Aspecto interessante a ser observado é o fato de um autor amazonense escolher um contexto boliviano para contar sua estória, em um livro no qual a

\footnotetext{
${ }^{3}$ É necessário ressaltar que, embora o termo esteja sendo usado neste artigo para referir-se às relações de poder entre colônia e metrópole, seu alcance e abrangência vão muito além destas relações, podendo se expandir para uma reflexão que está diretamente relacionada com as minorias inseridas em determinados contextos hegemônicos sejam eles políticos, culturais, morais, econômicos ou sociais; ou seja, o termo pós-colonial traz em si uma natureza multifacetada. Para Ella Shohat, citada por Mata, deveria se tratar de um substantivo plural, a saber, "pós-coloniais", "que são agora as mulheres, as minorias étnicas, as minorias sociológicas, os camponeses, os dissidentes ideológicos, os críticos do sistema políticos, enfim, os marginalizados do processo de globalização económica, geradora de periferias culturais.” (apud MATA, 2008, p. 10)
} 
maioria dos contos são ambientados, ou fazem fortes referências, à cidade de Manaus e ao Estado do Amazonas. Este conto específico apresenta, portanto, um distanciamento geográfico com relação aos outros contos do livro no que diz respeito ao espaço escolhido para a ação a ser narrada. Com este texto Linhares parece, de modo estratégico, afastar espacialmente as realidades amazônica e boliviana para, ao mesmo tempo, aproximá-las de outro modo.

Ora, se olharmos para o passado destas duas regiões e fizermos uma comparação, será possível perceber pontos em comum entre elas; vamos perceber que a aproximação entre estes dois espaços distintos é, principalmente, histórica. Pois, se por um lado existe um distanciamento geográfico entre estes dois espaços, por outro existe uma aproximação histórica no sentido de que ambos os espaços compartilham um passado marcado pela presença colonial em seus territórios. Portanto, se a geografia os separa, o passado marcado pela presença colonizadora os aproxima e os coloca em posição de convergência.

Este passado, comum aos dois espaços, emerge emblematicamente em uma rebelião indígena contra os brancos descendentes de espanhóis colonizadores nesta narrativa. Deste modo, o texto literário em questão já começa a mostrar, em seu interior, curiosos indícios desta condição histórica comum não só ao Amazonas e à Bolívia, mas, metonimicamente, a todos os países colonizados do continente latino-americano, um continente que traz em sua lembrança histórica as marcas profundas da presença colonial. Este conflito central entre índios e brancos, narrado por Linhares, será nossa porta de entrada no texto.

"Revolta" é uma das palavras que aparece na primeira linha do conto de Erasmo Linhares. A palavra já traz em si uma carga semântica que nos remete a uma ideia de tensão entre um poder constituído e seus "súditos"; remete-nos a uma ideia de insubmissão, neste caso, coletiva, à autoridade que, obviamente, é aquela que está em posição de força.

Esta revolta é comandada pelo personagem Juan, índio quetchua que nasceu e fora criado até os vinte anos no povoado por Doña Morales (matriarca de uma família espanhola que vivera sempre em meio aos índios quetchuas e aimarás que moravam e viviam como serviçais em sua propriedade). $\mathrm{O}$ ambiente, que sempre fora palco de hostilidades entre brancos e índios, vai tornar-se cenário de uma rebelião indígena. Durante o sangrento confronto, a matriarca permanece segura dentro do casarão, rodeada de luxo e requinte enquanto toca uma valsa ao piano. O casarão será invadido por Juan que, inicialmente, tem a intenção de matá-la, mas não chega a concretizar este objetivo, pois ao estar sozinho diante dela desiste da intenção, ajoelha-se e a chama de "madre", enquanto ela afaga sua cabeça; assim termina o conto de Linhares. 
Como fio condutor desta análise, faz-se necessário desde já, pensar estes dois personagens (Juan e Doña Morales) como uma representação desta tensão antagônica entre colonizador e colonizado, entre América Latina e Ocidente.

Juan, tomado como representação desta condição assumida pelo "novo continente" após o contato com o colonizador europeu, é um personagem que traz em si as marcas da imposição cultural e discursiva colonial; seu nome é um bom exemplo disso, pois possui um nome que não é tradicional de sua cultura, mas da cultura do colonizador. Não foi seu povo que o nomeou, mas os ocupantes estrangeiros. Sobre o vocábulo "nome”, nos diz o dicionário:

antropônimo dado a uma criança ao nascer, no batismo ou em outra ocasião especial, de acordo com a cultura e os costumes de cada povo e pelo qual ela é conhecida e chamada; [...] palavra que se agrega ao prenome para indicar sua origem (quem é seu pai, seu clã, seus antepassados, sua aldeia ou cidade, a profissão tradicional da sua família etc.). (HOUAISS, 2001)

Compreende-se, com isto, que o nome "Juan" assume um caráter emblemático neste sentido, pois, tem o propósito não apenas de civilizá-lo, mas também de distanciá-lo ou desvinculá-lo de sua cultura, de sua origem, de sua própria história. A palavra “Juan” assume, neste sentido, uma característica de produção discursiva do outro na medida em que o estrangeiro não permite que o indivíduo (ou cultura) nomeie a si mesmo, não permite que ele escolha o modo como pretende ser chamado por si e pelo outro. Vale ressaltar que, em um contexto colonial, é a cultura do estrangeiro que prevalece, na maioria das vezes de modo violento, sobre a cultura do colonizado.

Deste modo, o olhar preponderante é o olhar daqueles que estão em posição de força; o olhar exótico, noção que nos direciona imediatamente à ideia de um continente latinoamericano historicamente pensado e estruturado social, política, econômica, ideológica e imaginariamente pelos moldes ocidentais. Um continente sendo percebido e compreendido não através de seus próprios olhos, mas a partir de uma ótica ocidental; impossibilitado, portanto, de escrever sua própria história. Impossibilitado de dizer-se a si mesmo e ao mundo.

“[...] Avançavam obedientes às ordens de Juan - um índio quetchua que nascera pelas mãos de Doña Morales e em cuja casa vivera desde o primeiro choro até os vinte anos [...]” (LINHARES, 2005, p. 56). A noção de produção discursiva do outro assume, neste momento do texto, aspectos mais interessantes, pois é o momento em que os personagens Juan e Doña Morales aparecem correlacionados pela primeira vez nesta narrativa. A natureza desta primeira relação dos personagens é o ponto interessante a ser abordado aqui, dada a representação simbólica dos personagens adotada nesta análise. 
O fato de Juan ter nascido pelas mãos de Doña Morales assume um significado importante, pois foi ela que o trouxe ao mundo (assim como as culturas latino-americanas também somente "nasceram para o mundo" após terem sido avistadas e, principalmente, narradas pelo discurso ocidental). Isto nos faz pensar nos povos e culturas deste continente como uma espécie de invenção do Ocidente a partir do ato do descobrimento; esta invenção, ou ainda, percepção do Novo Mundo a partir de uma ótica ocidental seria o discurso que se consolidaria ao longo da história; o discurso objeto de reflexão e questionamento de uma postura pós-colonial que busca nomear-se a si mesma e contra-escrever este discurso.

A América Latina vem se delineando ao longo da história, portanto, como uma invenção da mentalidade europeia, como realmente nascida pelas mãos do Ocidente, porque modelada, estruturada física e culturalmente pelo pensamento ocidental que, como parte de seus objetivos, buscava homogeneizar o novo continente sob a égide de seu pensamento, tornando-o assim "igual”, uma espécie de extensão de si mesmo para além do oceano.

Como se pode perceber, a noção de globalização não é algo novo; principalmente se pensarmos na globalização como um processo hegemônico de homogeneização de culturas e identidades em escala mundial, como o quer Alberto Moreiras. O autor chama este processo globalizante de a "macronarrativa da modernidade", que seria exatamente esta expansão global do pensamento, da consciência e da própria identidade europeia. Mas esta intenção acabou encontrando oposições ao seu avanço hegemônico, ou seja, é uma "globalidade fisssurada" (MOREIRAS, 2001 p. 79).

Aqui, Moreiras (2001) faz uma ressalva ao fato de que, já que está falando de um processo imperial em nível planetário, seria mais sensato entender estes gestos de oposição não como fissuras da narrativa, mas como "fissuras na narrativa", uma vez que elas não funcionam externamente ao processo, mas no interior dele. Estas atitudes de resistência, esta negação aos avanços da modernidade, este bloqueio às reproduções da consciência macronarrativa moderna é o que o autor vai chamar de "globalidade negativa".

Durante a leitura deste conto percebe-se que a vila, na qual se dão os acontecimentos da estória, é, em si, um microcosmo narrativo desta modernidade imperial, uma vez que a paisagem foi modificada para parecer-se com a metrópole; as habitações nativas foram derrubadas para darem lugar às construções cujas arquiteturas intentam assemelhar-se com a metrópole; os hábitos, a língua e a cultura lembram a metrópole. A praça, espaço ocupado pelos índios e onde se dão os confrontos, é um exemplo disso; a casa onde Doña Morales permanece tocando, ao piano, uma valsa que ecoa por toda a narrativa também atesta muito bem esta ideia: 
[...] Por sobre o pequeno muro do cemitério, numa suave colina verde, do outro lado do estreito vale, luzia ao sol a branca casa senhorial dos Baptista de Morales. [...] Nas amplas salas da grande casa o silêncio só era maculado pelo canto intermitente dos canários engaiolados e pelo som suavíssimo, quase etéreo do piano; estalidos secos das juntas centenárias de algum móvel espanhol. [...] (LINHARES, 2005, p. 57)

Portanto, a revolta indígena neste conto se configura como uma fissura no interior deste espaço hegemônico globalizante; uma fissura pós-colonial. Ou seja, a insurreição dos índios funciona como uma negação desta globalidade hegemônica ocidental representada aqui, principalmente, pela figura de Doña Morales. O ato de insubmissão pode ser lido, deste modo, como uma representação do discurso pós-colonial na medida em que afronta e questiona o modelo de organização social estabelecido, suas desiguais relações de poder afirmadas pela presença colonial e baseadas na supremacia cultural e racial do estrangeiro. A revolta é uma forma de criar um espaço no qual a cultura nativa oprimida possa existir, o que a constitui, portanto, em uma resposta ao processo civilizador. Mas qual a natureza desta resposta sugerida por Linhares nesta narrativa?

O esclarecimento desta questão passa pela compreensão do intrigante final deste conto; para compreendê-la será necessário tomar a ideia de produção discursiva do outro, ou ainda, de nascimento do Novo Mundo a partir da ótica imperial e inverter a percepção para obter um outro olhar. Antes, porém, seria interessante conhecermos o momento alto desta narrativa, a saber, a cena em que o índio Juan invade a casa senhorial e se aproxima silenciosamente de Doña Morales para matá-la. Vale à pena transcrever os belos parágrafos que finalizam este conto de Erasmo Linhares:

Em nenhum momento interrompeu os movimentos cadenciados e a valsa fluía contínua, encantadora. Juan deteve-se à distância de um passo, e, por sobre o ombro encurvado, pôde ver as finas veias azuis das mãos, formavam uma teia complicada sobre a pele branca desenhada de rugas. Apertou fortemente o cabo do facão e, por um breve instante, considerou se ela o reconheceria se, num salto rápido, se postasse ao seu lado e gritasse-lhe o nome, antes de decepar-lhe o esquio pescoço com um golpe firme e certeiro. A valsa continuava fluindo, dolente. Doña Morales movimentava os braços e o corpo balançava a cada gesto, como se marcasse com isso o som de cada nota extraída. Juan apertou mais firmemente o punho da arma e sobressaltou-se, o coração bateu num salto contra os músculos do peito, quando a velha senhora disse sem interromper a música - Juan? E como não ouvisse a resposta, completou: Juan, chega-te a mim, filho. O índio afrouxou a tensão sobre o punho do machete e pendeu um pouco para a frente. Depois, mansamente, deu um passo e ajoelhou-se ao seu lado. Baixou a cabeça e disse num sussurro Madre. [...] Doña Morales suspendeu a mão direita do teclado e pousou-a 
sobre os negros cabelos de Juan. [...] - Hijuelo, disse numa voz muito doce. (LINHARES, 2005, p. 58- 59).

Dois pontos neste parágrafo são particularmente importantes para a conclusão desta análise. O primeiro deles é a não concretização do assassinato pelo índio Juan; e o segundo diz respeito à posição de subalternidade, assumida pelo personagem no final do conto.

No primeiro caso, o ato de não matar Doña Morales pode ser usado para significar uma consciência da importância da presença colonial europeia para a formação das culturas e identidades latino-americanas contemporâneas; esta formação se dá em forma de um trauma inicial gerado pela conquista, pela derrota e também através de todas as subsequentes negociações, adaptações, concessões e resistências implementadas pela cultura nativa no interior de um contexto hegemônico de unificação cultural com o qual está constantemente em tensão. É neste ponto que nasce o “outro olhar" proposto por este artigo, pois, se a experiência do descobrimento, a partir de uma ótica ocidental, pode ser considerada como a representação do nascimento da América Latina para o mundo, ao invertermos a ótica e tomarmos o ponto de vista do colonizado neste contexto, talvez a palavra mais adequada a ser utilizada fosse "renascimento".

Ora, após o choque da conquista, as culturas do "Novo Mundo" foram, de muitas formas, gradativamente sendo destruídas e sua sobrevivência dependia de novas estratégias e posturas diante de uma política colonial uniformizante, ou seja, estas culturas precisaram renascer. Renascer, neste sentido, significava encontrar seus próprios mecanismos de defesa e auto-sobrevivência em uma realidade modificada pela experiência colonial; significava encontrar métodos de coexistência com a cultura colonizadora através de uma reconfiguração cultural dentro de um contexto outro que lhe era despoticamente imposto.

Em outras palavras, renascer significava adaptar-se à cultura opressora do colonizador de um modo que fosse possível manter os traços da identidade cultural nativa que ainda existiam; ou que ainda podiam ser lembrados. Tal adaptação encontra terreno fértil em um processo de mestiçagem que opera através da interpenetração cultural das partes em conflito, na qual a assimilação crítica e consciente dos impulsos externos se configura como resistência, como resposta.

Assim sendo, nesta inversão de ótica, percebe-se, não que a América Latina nasce do olhar europeu, mas que a imposição hegemônica deste olhar gera, nas culturas deste continente, uma necessidade premente de renascimento, e, ao renascerem, renascem híbridas. E foi este "hibridismo sociocultural que marcou a formação da América Latina" (FANTINI, 2008, 
p.169); uma formação híbrida que traz em si um paradoxal amalgama de culturas díspares que geraria, a partir de então, uma identidade intercontinental.

Por conseguinte, uma das essenciais características da cultura Latino-americana seria exatamente o "híbrido"; sendo, portanto, impossível a existência de uma unidade totalmente homogênea. E a dificuldade ou relutância em aceitar tal fato acentua uma dicotomia meramente beligerante que se fecha ao diálogo e com isso anula as possibilidades de equilíbrio e crescimento a partir desta interface.

Ao comentar sobre a realidade da nacionalidade brasileira (reflexões que, metonimicamente se estendem às outras nações latino-americanas), Antonio Candido, parafraseado por Fantini, nos diz que "caso não se considere a urgente necessidade de assumirmos nossa multiplicidade cultural, étnica, literária, estará comprometida a compreensão de uma nacionalidade complexa como a nossa" (FANTINI, 2007, p. 125). Assim, a aceitação de uma identidade heterogênea, de uma nacionalidade complexa em sua multiplicidade deve ser considerada com vital relevância nas reflexões culturais, étnicas e literárias concernentes a este contexto. Tal aceitação é importante para a construção de uma noção de nacionalidade crítica e intercambiante com a cultura opressora; uma nacionalidade que se percebe e se aceita como heterogênea e que vê nesta heterogeneidade formas de resistência cultural, maneiras de reconstruir, compreender e valorizar seu passado através de uma reconfiguração discursiva que dialogue, conteste e analise criticamente o discurso hegemônico, ao qual resiste.

Percebe-se então a postura pós-colonial interpenetrando-se, dialogicamente, com a cultura ocupante como garantia de sobrevivência e como forma de melhor responder a ela. Para Antonio Candido,

\footnotetext{
Se entendermos por nacionalismo a exclusão de fontes estrangeiras, caímos no provincianismo; mas se o entendermos como cautela contra a fascinação provinciana por estas fontes, estaremos certos [...]. Se entendermos por nacionalismo o desconhecimento de raízes europeias, corremos o risco de atrapalhar nosso desenvolvimento harmonioso; mas se o entendermos como consciência da nossa diferença e critério para definir a nossa identidade, isto é, o que nos caracteriza a partir das matrizes, estamos garantindo o nosso ser que é não apenas "crivado de raças" (como diz um poema de Mário de Andrade), mas também de culturas. (apud FANTINI, 2007, p. 126)
}

Por isso, não faria sentido negar o outro que, por sua vez, já é parte da essência composicional de sua cultura. Em outras palavras, tentar buscar uma autonomia total abolindo e negando radicalmente aspectos da cultura europeia metropolitana seria buscar destruir parte de sua própria essência híbrida. A atitude de Juan em retroceder à intenção de matar Doña Morales que, nesta análise, tomamos como alegoria da própria permanência colonizadora espanhola, ou 
ainda, da cultura europeia e seus traços culturais neste continente, pode ser tomada como símbolo desta consciência híbrida que percebe esta relação de alteridade como necessária. Matar Doña Morales seria aniquilar uma parte de si mesmo.

Quanto à posição de inferioridade que Juan assume no final da estória, também tratase esta de um gesto ligado ao reconhecimento desta identidade e das formas de resistências articuladas pelas culturas nativas colonizadas. Tais culturas, após este renascimento relatado acima, adquirem uma identidade do "entre-lugar", aquela que vive e se articula constantemente através de uma tensão entre o que restou de si e os etnocêntricos influxos externos do conquistador europeu. É neste espaço de assimilação e oposição que se engendram ajustes, redefinições, negociações, resistências e concessões que nem sempre se dão de modo pacífico. O colonizado é aquele que tem como matéria prima para suas construções simbólicas a ruína de seu passado histórico-cultural, o qual está em constante tensão com o impulso modernizador, ou seja, não trabalha com um passado vívido e reluzente, mas com os escombros deste que precisa ser constantemente pensado e articulado dentro de um contexto hegemônico.

Esta articulação quase sempre paira entre a assimilação e a resistência. O fato de Juan se ajoelhar diante de Doña Morales faz dele um personagem ambíguo que oscila, ao longo da narrativa, entre uma postura de revolta e questionamento e uma postura de sujeição ao poder europeu. Trata-se de um personagem contraditório, se visto por este prisma; a mesma contradição que marca a formação da identidade latino-americana a qual representa neste conto de Linhares; a mesma contradição que engendra as ações e posturas pós-coloniais.

É oportuno citar, neste sentido, o pensamento de Anthony K. Appiah que vê "a póscolonialidade como lugar em que se operam as contradições do colonial, ora em sinergia, ora em competição" (apud MATA, 2008, p. 11), portanto, paradoxal. As atitudes de Juan representam a necessidade de uma consciência que reconheça a relevância de um comportamento dialógico e equilibrado com a cultura estrangeira ocupante; a necessidade de se buscar um meio-termo de comportamento intelectual e cultural característico desta identidade do "entre-lugar" que paire, como diria Cornejo Polar, "entre a obediência e a rebelião" (apud Mata, 2008, p. 3).

Obediência não no sentido de submissão, mas no sentido de reconhecimento dos aspectos positivos e das contribuições do ocupante estrangeiro para o fortalecimento da cultura nativa. Assim, a postura pós-colonial traz em sua natureza um caráter crítico de reflexão sobre si mesma e sobre o outro que se constitui como antagônico necessário e parte de sua 
constituição que não deve ser ignorado. Neste sentido, é apropriado o pensamento de Inocência Mata:

[...] embora possa parecer paradoxal, o pós-colonial denuncia a sua marca de dependência e um compromisso contraditório com o empreendimento que o precedeu e possibilitou e que, para combater, tem de digerir - o que, a meu ver, não tem conseguido, antes antagonizado as diferenças. Para criticar o colonial, o pós-colonial teria de se imbuir do colonial, incorporá-lo, dialogar com ele para o descrever e prescrever [...] ( MATA, 2008, p. 11)

Portanto, ao tomar a tensão manifestada por Juan e suas atitudes neste conto como representação da tensão histórica vivida pelo continente latino-americano, foi possível perceber a posição de paradoxo cultural e histórico deste; sua condição de "sujeito" que já não é o que era, "pré-moderno", digamos assim (se pensarmos em 1492 como a chegada da "modernidade" neste lado do atlântico), e, ao mesmo tempo, está longe de se tornar totalmente "moderno" (no sentido de expansão global homogeneizante do pensamento hegemônico ocidental) ${ }^{4}$.

Ou seja, este continente jamais poderá voltar a ser o que era, e, ao mesmo tempo, resiste à possibilidade de vir a ser totalmente assimilado por esta expansão hegemônica da identidade ocidental. Permanece então neste interstício entre o "ser" e o "não-ser"; entre a ânsia de resgatar, de reviver através da memória, da palavra ou de qualquer outro modo traços de sua cultura e de sua história que já não existem mais, e a impossibilidade de se desvincular totalmente do contato com aquele que, historicamente representa o causador de sua ruína.

Mas a tragédia da região não poderia ser também sua redenção? Nos diz Márcio Souza em seu artigo Amazônia e Modernidade (2002). Ampliando a reflexão para todo o continente, a resposta é sim, no sentido em que os conhecimentos e avanços científicos europeus talvez possam ser utilizados para compreender, reescrever e fazer a história sob outra perspectiva. Assim como os índios, neste conto de Linhares, usam carabinas em sua revolta, ou seja, se apoderam das armas criadas com os estudos, ciência e tecnologia do colonizador e as utilizam a seu favor na luta por sua libertação, o que nos propõe Márcio Souza não é, senão, uma apropriação do conhecimento. E esta apropriação se constitui como uma abertura assimiladora para absorver criticamente o outro.

Porém, esta forma de discurso só seria profícua se essa tomada do conhecimento Ocidental impulsionasse uma produção intelectual voltada para um mergulho na própria

\footnotetext{
${ }^{4}$ Parafraseando Walter Mignolo, Lugarinho observa que "a globalização seria apenas mais um capítulo deste processo que teria tido seu alvorecer no século XIV, quando o homem europeu alargava seus horizontes geográficos e submetia à sua lógica os povos de outros continentes, elevando à universalidade a sua forma particular de compreender o mundo. (LUGARINHO, 2010, p. 259)
} 
cultura, para um ato de autoconhecimento e compreensão interna que propiciasse uma melhor análise das potencialidades e possibilidades do continente. Tal análise geraria posturas e tomadas de atitude que seriam benéficas no que diz respeito à vitalização cultural, e, consequentemente, se expandiria ao âmbito econômico, político, social e humano; geraria, no final das contas, a possibilidade de ver-nos com nossos próprios olhos.

Caso contrário, este discurso serviria apenas como velado elemento aculturador; ou ainda, para aqueles tomados de um ressentimento histórico, como mero instrumento de negação do outro e não como ferramenta de autocompreensão propulsora de mudanças; serviria apenas para usar a ideia de pós-colonialidade como justificativa para as mazelas e o subdesenvolvimento e não como ponto de partida para uma produção ampla de conhecimentos sobre a própria região; uma produção que pode, e deve ir além das fronteiras latino-americanas em um movimento de dentro para fora.

Portanto, um uso produtivo deste discurso precisa rever suas formas de relação com a "metrópole", ao invés de simplesmente privilegiar o mero conflito dicotômico. É preciso perceber o diálogo como forma de resistência, pois, o debate simplesmente antagonista, dicotômico e beligerante acaba se sobrepondo à troca intelectual de reflexões que favoreceriam uma melhor compreensão da realidade em um âmbito muito mais profundo e abrangente.

\section{REFERÊNCIAS BIBLIOGRÁFICAS}

AGUALUSA, José Eduardo. O ano em que zumbi tomou o Rio. $1^{\text {a }}$ ed. Rio de Janeiro: Gryphus, 2008.

- O Brasil é Colônia. Época, Set. 2004. Disponível em: http://revistaepoca.globo.com/Epoca/0,6993,EPT808282-1666,00.html. Acesso em: 28 Nov. 2017.

Bosi, Alfredo. História concisa da literatura brasileira. 43ª ed. São Paulo: Cultrix, 2006.

FANON, Frantz. Os condenados da terra. Trad. Enilce Albergaria Rocha; Lucy Magalhães. Juiz de Fora: Editora UFJF, 2002.

FANTINI, Marli. Águas turvas, identidades quebradas: hibridismo, heterogeneidade, mestiçagem e outras misturas. In: ABDALA JUNIOR, Benjamim (org.). Margens da cultura: mestiçagem hibridismo \& outras misturas. - São Paulo: Boitempo, 2008. p. 159-180.

Hatoum \& Rosa: matizes, mesclas e outras misturas. In: CRISTO, Maria da Luz Pinheiro de (org.). Arquitetura da memória: ensaios sobre os romances Dois irmãos, Relato de um certo oriente e Cinzas do Norte, de Milton Hatoum. Manaus: UFAM; UniNorte, 2007, p. 119-144. 
HOUAISS, Antônio. Dicionário Eletrônico Houaiss da língua portuguesa 1.0. Ed. Objetiva Ltda. Dez/ 2001.

LINHARES, Erasmo. O tocador de charamela. Tenório Telles (org.). $3^{\text {a }}$ ed. - Manaus: Editora Valer/ Governo do Estado do Amazonas/ Edua/ UniNorte, 2005.

LUGARINHO, Mário César. Globalização, homogeneização cultural e literatura. In: CAVALHEIRO, Juciane (org.). Literatura, Interfaces, Fronteiras. - Manaus: UEA Edições, 2010. p. 253-266.

MATA, Inocência. O pós-colonial nas literaturas africanas de língua portuguesa. In: x congresso internacional da aladaa (Associação Latino-Americana de Estudos de Ásia e África), 2000, Rio de Janeiro. Cultura, poder e tecnologia: África e Ásia face à globalização. Rio de Janeiro, 2000. Disponível em: http://bibliotecavirtual.clacso.org.ar/ar/libros/aladaa/. Acesso em: 28 Nov.2017.

A crítica literária africana e a teoria pós-colonial: um modismo ou uma exigência? $\mathbf{O}$ Marrare - Revista de Pós-Graduação em Literatura Portuguesa da UERJ. Rio de Janeiro, $\mathrm{N}^{\circ}$ 8, 2008. Disponível em: www.omarrare.uerj.br/numero8/inocencia.htm. Acesso em: 26 Fev, 2012.

MOREIRAS, Alberto. A exaustão da diferença: paradigmas do latino-americanismo. Trad. Eliana Lourenço de Lima Reis. Belo Horizonte: Editora UFMG, 2001.

MOURALIS, Bernard. As contraliteraturas. Trad. António Filipe Rodrigues Marques; João David Pinto Correia. Coimbra: Livraria Almedina, 1982.

SAID, Edward W. Orientalismo: o Oriente como invenção do Ocidente. Trad. Rosaura Eichenberg. São Paulo: Companhia das Letras, 2007.

SANTOS, Eloína Prati dos. Pós-colonialismo e Pós-colonialidade. In: FIGUEIREDO, Eurídice (Org.). Conceitos de literatura e cultura. $2^{\text {a }}$ Ed. Niterói: Editora UFJF/ EdUFF, 2010. p. 341 365.

SOUZA, Márcio. Amazônia e modernidade. Estudos avançados, Vol. 16, No 45. São Paulo Mai/Ago, 2002. Disponível em: http://www.scielo.br/scielo.php?script=sci_arttext\&pid=S0103-40142002000200003. Acesso em: 28 Nov, 2017.

Recebido em: 29/11/2017

Aprovado em: 20/02/2018

Publicado em: 01/07/2018 